\title{
Exploring Association of OD Values with Organizational Perceived Effectiveness: Case of Small and Medium Enterprises
}

\author{
Muhammad Kashif Razzaque Khan ${ }^{1}$ \\ Dr. Nadeem A. Syed ${ }^{2}$
}

\begin{abstract}
A value culture always plays a significant role in organization development. Although the contemporary business organizations are gradually realizing the importance of these values in enhancing organization effectiveness, most of the organizations in Pakistan are still in dire need to adapt the values of openness, trust, authenticity and empowerment, collaboration and continuous organization learning in order to enhance organizational effectiveness and efficiency to survive or compete. Especially, the SME sector which constitutes a considerable part of Pakistani economy where majority of the firms have not been able to realize their full potential, the absence of value culture is constantly giving rise to low employee morale and less productivity and declining firms' performance. Using goal theory of organization effectiveness, this study explores the association of four important OD values: employee empowerment, open communications, employee collaboration and continuous learning on the perceived effectiveness taking the case of 20 small and medium enterprises located in Karachi. A hypothetic-deductive approach is adapted to obtain the findings. The results support that open communication, employee collaboration and continuous organization learning are significantly associated with the perceived goal achievement levels of the firms. A positive but statistically insignificant association is observed in case of employee empowerment. The regression analysis indicates that the selected four OD values significantly contribute to the perceived organizational effectiveness on the given four important goals of the firm. The findings of this study do not only contribute to the organizational development, but would also help the government and the concerned authorities to devise strategies to develop and reinforce the value system in SMEs to deal with effectiveness and productivity issues in this major sector.
\end{abstract}

Keywords: Collaboration, employee empowerment, goal theory, open communication, organizational effectiveness, organizational learning, SMEs

\section{Introduction}

Organizational Development (OD) values are becoming important as set of values and believes has become a constituent and integral part of organization development. These values often play an important role in determining the goals and methods that OD and Change experts use in their field. Although the modern business has realized the significance of these values, most of the Pakistani organizations are still in great need to acclimatize these values of openness, trust, authenticity, empowerment, and collaboration in order to enhance organizational effectiveness and efficiency. While OD programs attach great importance to value system of the organization, they also recognize that almost all organizations are unique and that the same resolution cannot essentially be applied at different firms.

${ }^{1}$ M. Kashif Razzaque Khan is Manager Credits \& Foreign Exchange, MCB Ltd., Karachi, kashifkhan1983@hotmail.com ${ }^{2}$ Dr. Nadeem A. Syed is Associate Professor, Management Sciences, SZABIST, Karachi, nadeem.syed@ szabist.edu.pk

\begin{tabular}{llll|l}
\hline JISR-MSSE & Volume 11 & Number 1 & Jaunary - June 2013 & 41
\end{tabular} 
In Pakistan, a significant part of the financial system consists of small and medium enterprises (SMEs) which are regarded as the locomotive economic expansion of the country. A prosperous SME sector has been known as the key to an affluent and rising economy. Significance of their position and role is clearly specified by various figures and statistics.

Management skills and expertise can be associated with the organizational performance and organizational makeup in all sizes of these firms. The managerial ability and skills relate to the performance of the enterprises. It has been presented in a number of studies that the performance of SMEs in Pakistan has been direly affected by the poor decision-making skills and abilities, especially in undersized organizations (Aaftab \& Raheem, 1986). The managers in some cases even take up a personalized supervision approach which results in economic inefficiencies of these organizations. The professional, enlightening and educational training of the business executives in these small firms has been considered as an important and significant support for these management styles.

The research is aimed at determining the relationship of various OD values with the organizational performance. The main objective of this research is to know the answer, whether the selected OD values (employee empowerment, open communication, employee collaboration and continuous inquisition and learning) can be linked with the overall goal achievement or effectiveness of the organization.

The findings of this research contribute to the organizational development literature in a numeral of significant ways. It adds authenticity to the theoretical conceptualization that an organization culture that promotes these OD values can improve the organizational efficiency and effectiveness.

The research is limited to data collection from organizations which are located in Karachi only in manufacturing and services sectors. The data presented in this study provides a fine indication of impact of values on firms' perceived performance of the region's SME sector. However, given the data limitations, they should not be taken as completely precise or representative of the entire sector.

\section{Literature Review}

Organizational effectiveness is the theory of how efficient firms are in achieving its goals. Organizational effectiveness has been considered a concept that is hard to measure directly so the proxy measures are often used to represent organization's effectiveness. Shetty (cited in Osborn, 1979, p.60) reported that major US corporations have profitability, growth, market share, product quality efficiency, financial stability and social responsibility as some of the goals. Kaplan and Norton (1992) emphasized that what companies should "balance" the financial perspective in this context. They argued that four perspective, including learning and growth, business process, customer and financials should be viewed to have a clear prescription of organizational effectiveness.

Weiss (1966) proposed that high quality organizations are both effective and efficient. Though there is never one prescription for the success or one predictor of what will make the organization successful, several recognizes characteristics are associated with effective organization. Highly effective organizations are extremely focused, customer centered , built

\begin{tabular}{l|llll}
\hline 42 & Jaunary - June 2013 & Volume 11 & Number 1 & JISR-MSSE
\end{tabular}


on marinating strategic networks and alliances dedicated to value in products, committed to positive learning and change, dedicated to fulfilling responsibilities to all stakeholders and committed to measuring progress against world-class stands of excellence.

Hurley et al (1992) coated a survey performed by ASTD (American Society of Training and Development), in response to question concerning the OD work respondent mentioned

- "Empowering employee" to act

- Shaping "Openness in Communication"

- To facilitate Possession of "Outcome and Process"

- To Promote a "Culture of Collaboration"

- To promote "Inquiry \& Continuous Organization Learning"

The magnitude of human resource in SMEs has been conceived by a member authors. Penning et al (1998) and Delman et al (2002) linked it to significant outcomes variables, including customer service, productivity of the firms and quality.

Ahmed and Cheema (2009) have argued that in this multifaceted environment the success of organization depends on transferring decisions making power to the front line employees so that first hand solution of problems could be provided to the customers. They advocated that establishing effective communication with the first line employees and sharing of information with them can enhance the quality of services and customers satisfaction.

Wendell (2009) considered employee empowerment is an important element in sky-scraping performance organizations. Lashley (1999) viewed employee empowerment beneficial to all organizations. He argued that the empowered employees are generally more productive and customer oriented. Newstorm (1993) empowerment also enhances employees' problem solving skills.

Open communication refers to a policy that aimed at ensuring that employees have maximum information of their firms and workings. Communication environment supports employees by encouraging, by contributing in "Decision Making", and by trusting to give surety the integrity of information canals. Denton (1988) emphasized that "Communication solutions these days turn around greater information sharing and exchange of data among and within department. He highlighted many areas in which "Open Communication" can be applied to improve organizational performance \& staffs relations.

Sunders (2001) stated that open communication environment is characterized by the following:

1. Employees are heard and feel valued. Their suggestions and ideas and opinions are invited and appreciated regardless of gender, race, religion, language, culture, sexual orientation \& age etc.

2. Management has trust on employees

3. Creative dissent is rewarded or welcomed. Employees are encouraged to question, think and shape independent decision, and take responsibility for altering the ways business is completed. 
4. Employees are made aware of what is happening within the organization through formal as well as informal channels.

Openness in communication eventually rewards both the organization and individual in providing an environment where human flourish and enterprise grow. Hart (1996) has proposed open communication as one of their values of successful organizations.

Collaboration has been defined as the act of working together. Hoegl et al. (2004) see important elements of collaboration and teamwork as:

- In a work group, people help each other to obtain their task accomplished

- In firms, all work groups support each other in completing their tasks.

- Employees quickly settle their disputes and trust each other.

Hoegl (2004) explained that collaboration and teamwork within and across groups can forecast an organization's productivity and effectiveness. He indicated that trust is a serious success factor in firms which acts a key role in development high levels of collaboration \& teamwork.

One of the primary drivers in today's competitive business environment is the ability of an organization to learn effectively. Senge (1990) comments: "The rate at which organizations learn may become the only sustainable source of competitive advantage." So an organization committed to learning effectively must line up itself to value and reward learning to create behavior that results in a culture of learning within the organization. Argyris (1977) defines organizational learning as the process of "detection and correction of errors". Cummings (2004) states that organization learning involvements highlight the organizational structure $\&$ social procedures that allow teams \& employees to share \& learn more knowledge.

\section{Conceptual Framework}

Based on the literature review a conceptual framework has been developed to present a basis for the research. The proposed research model is shown in figure1: four variables are hypothesized to have a positive correlation with organizational effectiveness. The purpose of theoretical framework is to figure out the relationship between the organizational effectiveness and various which are considered vital for organizational development values i.e. employee empowerment, open communication, collaboration among employees and employee learning in the selected sector of the economy. In this study, the focus has been on these values as determinant of organizational effectiveness. The common theme among these variables is that organizational effectiveness has a significant level of association with the selected OD values.

To execute the research, different dependent and independent variables are defined for conceptual framework. The independent variables are OD values i.e., employee empowerment, open communication, employee collaboration and employee learning and organizational effectiveness is a dependent variable. These two variables have been taken to examine the perceived association between them i.e., determining the extent to which values are being considered as determinant of organizational effectiveness. It is apparent from the available literature that different values influence firms' ability to achieve their goals. The obtained data would help in examining the relationship between the organizational effectiveness and the four selected OD values.

44 Jaunary - June 2013

Volume 11

Number 1

JISR-MSSE 


\subsection{Research Hypotheses}

The study aims to test the following six hypotheses:

H1: There is a significant positive relationship between employee empowerment and organization effectiveness.

H2: There is a significant positive relationship between open communication and organization effectiveness.

H3: There is a significant positive relationship between employee collaboration and organization effectiveness.

H4: There is a significant positive relationship between continuous organization learning and organization effectiveness.

H5: Employee collaborations have significantly associated with the employee ability to communicate openly and employee empowerment.

H6: The four independent variables (employee empowerment, open communication, employee collaboration and continuous learning) significantly explain the variation in the dependent variable (perceived effectiveness / achievement level).

\section{Research Methodology}

The research is basically a hypothetic-deductive study. The content discusses the importance of OD values i.e., employee empowerment, open communication, employee collaboration and learning and their impact on perceived performance of the organization. The researcher has developed a proposition that the value structure in the organization plays a major role in organization's success. The selected four values help organization to attain its set objectives/goals in terms of output; product quality and firm's profitability thus enhance its effectiveness. This research assesses their importance and value in SME sector in Pakistan.

\subsection{Research Design}

The study uses a quantitative survey technique to collect the data and determines the association between the variables of organizational development values and effectiveness. The direction and strength of association of all independent variables have been measured to explain the dependent variable.

\subsection{Sample Selection, Method and Size}

For the purpose of research, those organizations were selected which come under SME in the light of the definition given by SME Policy 2007, Government of Pakistan. As per this policy definition organizations located in North Karachi and SITE were included in the study. The respondents are mostly the owner/managers, and supervisors, working in firms and have an adequate qualification and experience of running these small and medium conglomerates.

The research has been restricted to only manufacturing and service sectors. Therefore, nonprobability convenience sampling technique has been adopted in the research. Another rationale for using this sampling method is the limitation of time, and as the research is only

\begin{tabular}{lll|l}
\hline JISR-MSSE & Volume 11 & Number 1 & Jaunary - June 2013
\end{tabular} 
designed for Karachi; therefore, this category of non-probability convenience sampling technique is appropriate.

A sample of 120 individuals is selected based on 20 SMEs in manufacturing and services sectors. The questionnaires were distributed at three different levels (Owner- Managers / Manager, Supervisors, and workers) resulting in following sample breakup (based on proportional allocation). The allocation is 20 owners / managers, 40 supervisors, and 60 employees.

\subsection{Data Collection}

Both primary and secondary data was collected from a variety of perspectives to determine the perception of managers and supervisors with the existing value environment in their organization and was analyzed variable-wise, statistically by applying the various statistical tools. The research is quantitative in nature and a customized questionnaire, comprising total 22 questions, along with demographic factors are designed and distributed in various SMEs located in Karachi to collect the primary data. The five point Likert sort of technique was directed to evaluate how efficiently the individual mechanism of the values climate is operating. All questions are pre-tested.

\section{Data Analysis and Findings}

\subsection{Descriptive Analysis}

Most of respondents i.e., $71.7 \%$ for this study were from the manufacturing sector. Among them, majority of respondents were male and fall in the expereince category of 1-3 years and then above 10 years respectively. The most of the respondents fall under the age category of 20-30 years and belong to a monthly income of above Rs 60,000.

\subsubsection{Employee Empowerment}

When respondents asked about the employee empowerment (making work-related decisions, ideas sharing, exercising initiative and imagination and involvement in important business decisions) in their firms, the highest mean is observed for employee full authority to make various work related decisions with relatively lowest Standard Deviation (0.802). The next value is for contribution of ideas having mean of 4.22 and Standard Deviation 0.884 . The second lowest mean has been noticed for third dimension (exercising initiative and imagination) as 3.98 with Standard Deviation of 1.053. The lowest mean was observed for employee involvement in important business decisions with the highest Standard Deviation and lowest Variance (see Table 1).

The graph 1 shows that $90 \%$ respondents believe that employees in their firms make most of the work/job related decisions. $88 \%$ respondents said that he employees in their firms are 
encouraged to contribute ideas, $79 \%$ of the respondents agreed that employees are allowed to exercise initiative and imagination whereas only about $17 \%$ of the respondents revealed that employee in their firms are involved in the important decision of the business $(81 \%$ believe that employee are not involved).

Table 1

\begin{tabular}{|l|c|c|c|c|}
\hline \multicolumn{5}{|c|}{ Statistics } \\
\hline & $\begin{array}{c}\text { Make } \\
\text { most job } \\
\text { related } \\
\text { decision }\end{array}$ & $\begin{array}{c}\text { Allowed to } \\
\text { Encouraged } \\
\text { to contribute } \\
\text { Ideas }\end{array}$ & $\begin{array}{c}\text { exercise } \\
\text { initiatives } \\
\text { and } \\
\text { imagination }\end{array}$ & $\begin{array}{c}\text { Included in } \\
\text { important } \\
\text { decisions of } \\
\text { the business }\end{array}$ \\
\hline Mean & 4.25 & 4.22 & 3.98 & 2.38 \\
Std. & 0.802 & 0.884 & 1.053 & 1.139 \\
Deviation & 0.802 & 1.109 & 1.297 \\
Variance & 0.643 & 0.781 & 1 & 1 \\
Min & 1 & 1 & 5 & 5 \\
Max & 5 & 5 & 5 \\
\hline
\end{tabular}

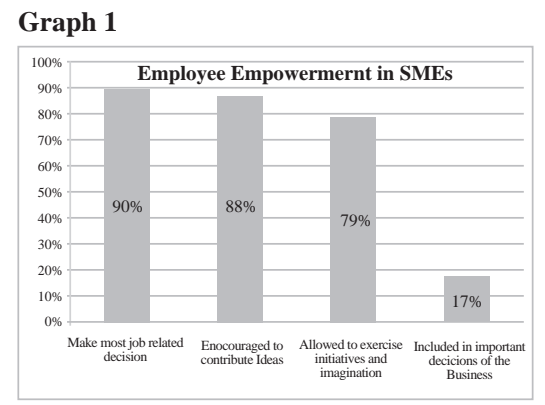

\subsubsection{Open Communication}

For an open communication environment, more or less same mean value has been observed for $1^{\text {st }}$ and $2^{\text {nd }}$ dimension. The lowest mean has been observed for suggestion invited from all employees with highest Standard Deviation and Variance. Informing about total organization working and freely communication with bosses has been noticed as mean of 4.17 and 4.19 with Standard Deviation of 0.901 and 0.910 respectively (see Table 2 below).

The graph 2 shows that almost $88 \%$ respondents believed that employees in their firms are informed about total organization and its working. Almost same proportion of the respondents indicated that employees at their work wetting are encouraged to communicate with their bosses freely and openly. Almost $70 \%$ of the respondents revealed that management invites and appreciates the opinions and suggestions about various business matters.

Table 2

\begin{tabular}{|l|r|r|r|}
\hline \multicolumn{4}{|c|}{ Statistics } \\
\hline & $\begin{array}{c}\text { Informing about } \\
\text { Total } \\
\text { Organization }\end{array}$ & $\begin{array}{c}\text { Employee freely } \\
\text { communicate } \\
\text { with bosses }\end{array}$ & $\begin{array}{c}\text { Suggestion } \\
\text { are invited } \\
\text { from all }\end{array}$ \\
\hline Mean & 4.17 & 4.19 & 3.5 \\
Std. & 0.901 & 0.91 & 1.092 \\
Deviation & 0.812 & 0.829 & 1.193 \\
Variance & 1 & 1 & 1 \\
Min & 5 & 5 & 5 \\
Max & & &
\end{tabular}

\section{Graph 2}

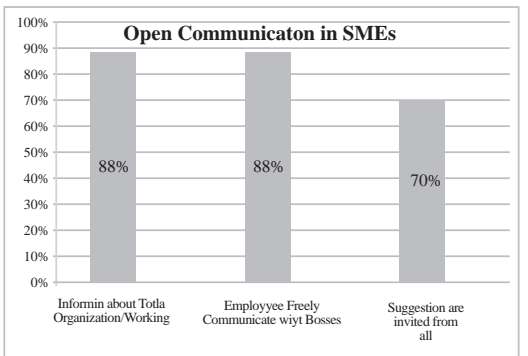

\subsubsection{Employee Collaboration}

The next set of questions was related to collaboration among employee at the workplace. Four elements of employee collaboration included Intra Group Cooperation, Inter Group Cooperation and Support, Conflict Settlement and Mutual Trust. The highest mean value has 
been observed for Intra Group and then for Inter Group collaboration with relatively lowers Standard Deviation. The other two dimensions got relatively lower mean values with higher Standard Deviation (see Table 3). The graph 3 shows that about $98 \%$ respondents believed that employees in their firms cooperate with each other to get their jobs done. Almost $95 \%$ respondents said that different work groups and teams cooperate and support each other. About $66 \%$ respondents reported that workers quickly resolve their conflicts whereas almost $50 \%$ respondents think that employees trust each other.

Table 3

\begin{tabular}{|l|r|r|r|r|}
\hline \multicolumn{5}{|c|}{ Statistics } \\
\hline & $\begin{array}{c}\text { Intra } \\
\text { Group } \\
\text { Cprtion }\end{array}$ & $\begin{array}{c}\text { Inter } \\
\text { Group } \\
\text { Cprtion }\end{array}$ & $\begin{array}{c}\text { Conflict } \\
\text { resolution }\end{array}$ & $\begin{array}{c}\text { Mutual } \\
\text { Trust }\end{array}$ \\
\hline Mean & 4.52 & 4.44 & 3.59 & 3 \\
Std. Deviation & 0.594 & 0.742 & 1.487 & 1.123 \\
Variance & 0.353 & 0.551 & 2.21 & 1.261 \\
Min & 2 & 2 & 1 & 1 \\
Max & 5 & 5 & 5 & 5 \\
\hline
\end{tabular}

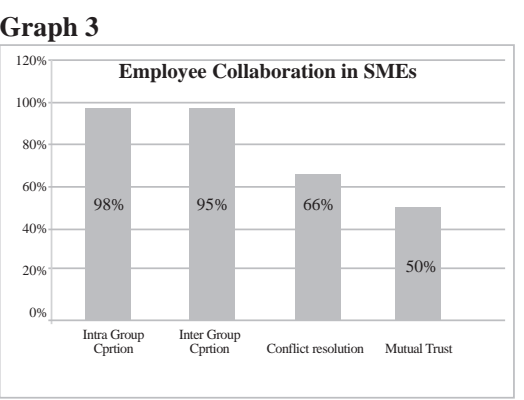

\subsubsection{Continuous Organization Learning}

The subsequently set of questions was related to continuous organization and employee learning. The respondents were asked three questions in this context. The response descriptive analysis of the responses reveals that the highest mean has been observed for organization constantly respond to the changing business condition with the lowest standard deviation. Almost $80 \%$ of the respondents believed that their organization facilitates employee learning at all levels. Almost $65 \%$ believed that their organization appreciate and reward employees for applying new knowledge and skills at work place. About $96 \%$ said that the management in their firms constantly responds to the changing business conditions and adjusts its system and policies, as shown in the graph 4.

Table 4

\begin{tabular}{|l|r|r|r|}
\hline \multicolumn{4}{|c|}{ Statistics } \\
\hline & $\begin{array}{c}\text { Facilitating } \\
\text { Employee } \\
\text { Learning }\end{array}$ & $\begin{array}{c}\text { Encouraging } \\
\text { and applying } \\
\text { new skills }\end{array}$ & $\begin{array}{c}\text { Responding to } \\
\text { changing } \\
\text { environment }\end{array}$ \\
\hline Mean & 4.02 & 3.51 & 4.31 \\
Std. Deviation & 1.119 & 1.316 & 0.719 \\
Variance & 1.251 & 1.731 & 0.518 \\
Min & 1 & 1 & 1 \\
Max & 5 & 5 & 5 \\
\hline
\end{tabular}

\section{Graph 4}

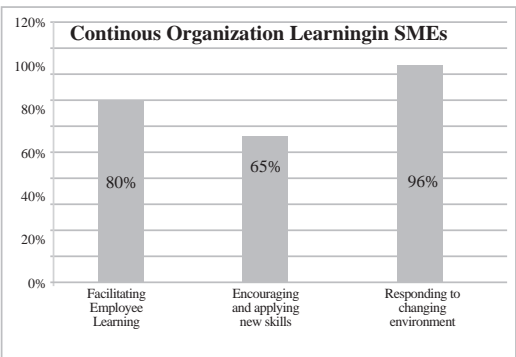




\subsubsection{Perceived Goal Importance}

Respondents were asked about their perceived importance of the given four goals viz Quantity of output produced, product quality, Cost Efficiency and Delivery performance (time) goals. About $94 \%$ of the respondents showed that output is somewhat/ very important in attaining effectiveness. About $98 \%$ respondents perceive quality somewhat/ very important in attaining effectiveness. Whereas perceived importance (somewhat/ very important) of cost and delivery goals in determining firm's success were reported as $93 \%$ and $89 \%$ (see graph 5 below).

Table 5

\begin{tabular}{|l|r|r|r|r|}
\hline \multicolumn{5}{|c|}{ Statistics } \\
\hline & Quantity & Quantity & $\begin{array}{c}\text { Cost } \\
\text { Efficiency }\end{array}$ & $\begin{array}{c}\text { Delivering } \\
\text { (Time) }\end{array}$ \\
\hline Mean & 4.3 & 4.16 & 4.08 & 3.93 \\
Std. Deviation & 0.751 & 0.485 & 0.805 & 0.73 \\
Min & 2 & 2 & 1 & 1 \\
Max & 5 & 5 & 5 & 5 \\
& & & & \\
\hline
\end{tabular}

Graph 5

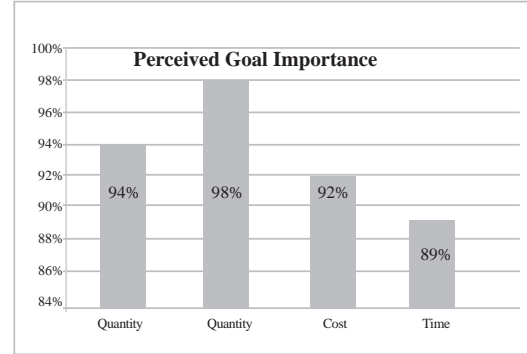

\subsubsection{Perceived Goal Achievement (perceived effectiveness)}

The descriptive details of perceived achievement levels for the given four goals are as follows: Almost $75 \%$ of the respondents report that they have somewhat or very much achieved their Quantity goals. 74\% have completely or somewhat achieved their goals about Quality and Cost efficiency. Almost $91 \%$ of the respondents revealed a positive attainment of their goals related to delivery performance, see graph 6.

Table 6

\begin{tabular}{|l|r|r|r|r|}
\hline \multicolumn{5}{|c|}{ Statistics } \\
\hline & Quantity & Quantity & $\begin{array}{c}\text { Cost } \\
\text { Efficiency }\end{array}$ & $\begin{array}{c}\text { Delivering } \\
\text { (Time) }\end{array}$ \\
\hline Mean & 3.78 & 3.78 & 3.58 & 4.58 \\
Std. Deviation & 0.804 & 1.065 & 1.058 & 1.105 \\
Min & 1 & 1 & 1 & 1 \\
Max & 5 & 5 & 5 & 5 \\
& & & & \\
\hline
\end{tabular}

\section{Graph 6}

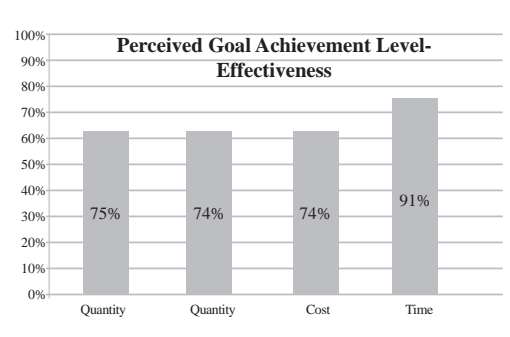




\subsection{Correlation Analysis}

Pearson's Correlation has been performed to study the track of association between the dependent and independent variables.

Table 7

\begin{tabular}{|c|c|c|c|c|c|c|}
\hline & & $\begin{array}{c}\text { Perceived } \\
\text { Effectiveness }\end{array}$ & \begin{tabular}{|c|} 
Employee \\
Empowerment
\end{tabular} & $\begin{array}{c}\text { Open } \\
\text { Communication }\end{array}$ & $\begin{array}{c}\text { Employee } \\
\text { Collaboration }\end{array}$ & $\begin{array}{c}\text { Continuous } \\
\text { Organization } \\
\text { Learning }\end{array}$ \\
\hline \multirow[t]{3}{*}{$\begin{array}{l}\text { Perceived } \\
\text { Effectiveness }\end{array}$} & $\begin{array}{l}\text { Pearson } \\
\text { Correlation }\end{array}$ & 1 & .125 & $.609 * *$ & $.527 * *$ & $.384 * *$ \\
\hline & Sig. (2-tailed) & & .177 & .000 & .000 & .000 \\
\hline & $\mathrm{N}$ & 120 & 120 & 120 & 120 & 120 \\
\hline \multirow{3}{*}{$\begin{array}{l}\text { Employee } \\
\text { Empowerment }\end{array}$} & Pearson & 125 & 1 & $313 * *$ & $664 * *$ & -007 \\
\hline & Sig. (2-tailed) & .177 & & .001 & .000 & .937 \\
\hline & $\mathrm{N}$ & 120 & 120 & 120 & 120 & 120 \\
\hline \multirow[t]{3}{*}{$\begin{array}{l}\text { Open } \\
\text { Communication }\end{array}$} & $\begin{array}{l}\text { Pearson } \\
\text { Correlation }\end{array}$ & $.609 * *$ & $.313 * *$ & 1 & $.631 * *$ & -.118 \\
\hline & Sig. (2-tailed) & .000 & .001 & & .000 & .201 \\
\hline & $\mathrm{N}$ & 120 & 120 & 120 & 120 & 120 \\
\hline \multirow[t]{3}{*}{$\begin{array}{l}\text { Employee } \\
\text { Collaboration }\end{array}$} & $\begin{array}{l}\text { Pearson } \\
\text { Correlation }\end{array}$ & $.527 * *$ & $.664 * *$ & $.631 * *$ & 1 & $.315 * *$ \\
\hline & Sig. (2-tailed) & .000 & .000 & .000 & & .000 \\
\hline & $\mathrm{N}$ & 120 & 120 & 120 & 120 & 120 \\
\hline \multirow{3}{*}{$\begin{array}{l}\text { Continuous } \\
\text { Organization } \\
\text { Learning }\end{array}$} & $\begin{array}{l}\text { Pearson } \\
\text { Correlation }\end{array}$ & $.384 * *$ & -.007 & -.118 & $.315^{* *}$ & 1 \\
\hline & Sig. (2-tailed) & .000 & .937 & .201 & .000 & \\
\hline & $\mathrm{N}$ & 120 & 120 & 120 & 120 & 120 \\
\hline
\end{tabular}

**. Correlation is significant at the 0.01 level (2-tailed).

The above-mentioned Table represents the correlation matrix between OD values variables i.e. employee empowerment, open communication, employee collaboration and employee $\&$ organization learning on the dependent variable Organizational Effectiveness (perceived attainment of quantity, quality, cost efficiency and delivery goals)

The relationship of open communication, employee collaboration and continuous learning with the dependent variable organizational perceived effectiveness has been found positive and significant as were expected. Employee empowerment has positive but an insignificant association with dependent variable $r=0.125$. The most significant associated variable is open communication $r=0.609, p<0.001$ with perceived organizational effectiveness. The

\begin{tabular}{l|llll}
\hline 50 & Jaunary - June 2013 & Volume 11 & Number 1 & JISR-MSSE
\end{tabular}


findings are supported by Odom et al. (1990) who relate the firm's achievement level of its various goals with an open and informal communication climate.

The second and moderate correlation is found between employee collaboration and organizational effectiveness i.e. $\mathrm{r}=0.527, \mathrm{p}<0.001$ which means that a collaborative and supportive work environment has linked with organizational performance. The findings are supported by Hoegl (2004) who determined a positive link between teamwork and employee collaboration and organization's productivity and effectiveness.

The third positive and significant association was found between continuous organization learning and organizational effectiveness $(r=0.384, \mathrm{p}<0.001)$. The finding is reliable with the result of the survey conducted by the "Australian Manufacturing Council" AMC-1994 and "Ministry of Commerce" MC-1999 observed learning and employee development is the key factor linked with organization success.

The above-mentioned correlation matrix indicates that the first hypothesis (H1) i.e., employee empowerment is significantly associated with organizational effectiveness, is not substantiated. On the other hand, the remaining hypotheses ( $\mathrm{H} 2, \mathrm{H} 3, \mathrm{H} 4, \mathrm{H} 5, \mathrm{H} 6)$ have been supported by the test.

\subsection{Regression Analysis}

The following tables show the regression analysis of the results. The model summary table shows the variation in the dependent variable i.e. perceived organizational effectiveness caused by the independent variables of employee empowerment, open communication, employee collaboration and continuous learning is 0.588. The ANOVA table explains that the F-Value of 40.726 is significant at the 0.001 level which means that H5 is substantiated. The beta values under standardized coefficients shows that open communication (having the highest value of beta) influences most the variation in the organizational effectiveness.

\subsubsection{Model Summary}

\begin{tabular}{|c|c|c|c|c|}
\hline & $\mathbf{R}$ & $\mathbf{R}^{\mathbf{2}}$ & Adjsd $\mathbf{R}^{\mathbf{2}}$ & $\begin{array}{c}\text { Standard } \\
\text { Error }\end{array}$ \\
\hline 0.1 & 0.767 & 0.588 & 0.574 & 0.24103 \\
\hline
\end{tabular}

Dependent Variable: Perceived Effectiveness

Predictors: Employee Empowerment, Open Communication, Collaboration, Continuous Learning

Table 8

\section{ANOVA}

\begin{tabular}{|c|c|c|c|c|c|}
\hline & $\begin{array}{l}\text {.Sum .of } \\
\text { Squares }\end{array}$ & .Df. & .Mean.Square. & .F. & .Sig. \\
\hline Regression & 9.464 & 10 & 2.366 & 40.726 & 0 \\
\hline Residual & 6.623 & 109 & 0.058 & & \\
\hline Total & 16.087 & 119 & & & \\
\hline
\end{tabular}

Dependent Variable: Perceived Effectiveness

Predictors: Employee Empowerment, Open Communication, Collaboration,

Continuous Learning

\begin{tabular}{lll|l}
\hline JISR-MSSE & Volume 11 & Number 1 & Jaunary - June 2013
\end{tabular}




\begin{tabular}{|l|c|}
\hline \multirow{2}{*}{ Empowerment } & $\begin{array}{c}\text { Standardized } \\
\text { Coefficient }\end{array}$ \\
\cline { 2 - 2 } Open Communication & Beta. \\
Collaboration & -0.094 \\
Continuous Org. & 0.686 \\
Learning & 0.511 \\
\hline
\end{tabular}

\section{Conclusion}

Much of the previous studies discussed the associations of OD values with a focus on large business firm's performance. Very few have explored the associations of empowerment, open communication, collaboration and continuous organization learning with organizational achievement of various organizational goals of the small and medium business enterprises. Therefore, the given research contribute to the rising flow on this relatively understudies are of the literature.

The study was aimed at examining the associations of the four important OD values, employee empowerment, open communication, employee collaboration and continuous learning on the perceived effectiveness of the SME firms. From the supported materials and study results, it is concluded the organizational principles like employee collaboration, open communication, and a culture of constant query and learning have significant relationship with achievement of various organization goals. It means that the organizations which have open communication climate, collaborative work environment and a culture of continuous employee and organization learning reports higher achievement levels on various organizational goals of output, quality, and efficiency and performance.

It should be noted that four variables discussed in the study contributing to the organization effectiveness of SMEs may contribute to it differently, for example, employee empowerment may have relatively less impact on organization capability to achieve its goals as showed by this study. Hence this factor can be omitted or merged with each other factors. This will reduce this variable from the study and more prominent variables can emerge or the impact of other variables can be measured more precisely.

The result of significant positive correlation between open communication and organizational effectiveness shows that the capable firms have a high tendency to encourage employees to freely communicate with the bosses and invite and appreciate opinions and suggestions from all employees. The significant correlation of employee collaboration and organizational perceived effectiveness shows that the organizational capability to achieve the set objectives also depends on collaborative environment of mutual support and trust. Similarly, a culture that promotes employee inquisition and learning may also significantly contribute to greater organizational effectiveness. The result also shows that a collaborative work environment is significantly dependent on open communication and employee empowerment. The regression analysis indicates that he selected OD values (employee empowerment, open communication,

52 Jaunary - June 2013 $\quad$ Volume $11 \quad$ Number $1 \quad$ JISR-MSSE 
collaboration and continuous learning) significantly contribute to organizational effectiveness on the given four important goals of the SME firms.

\subsection{Recommendations}

The organizations must support these values in order to perform well and to attain optimum organizational performance goals. The SME sector is the backbone of the economy and can occupy a considerable position in the success of the country. The most of these firms have been facing problems of low productivity and efficiency caused by lack of business orientation \& capitalist, joined with an absence of a supportive value culture that promote high employee morale and productivity. Therefore, the findings of the study suggest that owners and managers must support and promote these values at their workplace.

The provincial and federal government should take measures to support and promote these values through awareness and training of the owners and managers of these small firms. Especially the government through the SME policy, in addition to meeting the general needs of the sector, must promote these OD values throughout the SME sector so that this important sector of the economy can realize its full potential and complete with its international counterparts.

\section{Areas for Further Research}

This study examined the associations of the four major OD values on perceived effectiveness of SMEs. However, a number of areas for future research can be suggested. It would be of interest to explore further how OD values effect profitability and other non-financial goals of the firms in real terms. It may also be investigated that what other values may contribute to effectiveness of the firms. The future research studies could be based on other varied theoretical approaches, including stakeholders, competing value and system resources to study a more comprehensive view of how OD values are associated with organization's growth and success.

\section{References}

Aftab, K., \& Rahim, E. (1986). The emergence of a small scale engineering sector: the case of tube well production in the Pakistan Punjab, Journal of Development Studies, 23, 30-32,

Ahmed, F., \& Cheema, F. ( 2009). The Role of Employee Empowerment in improving service industry: a case study of UBL. Proceedings of $13^{\text {th }}$ National Research Conference (NRC), Management, Social Sciences and Economics, SZABIST, Karachi.

Allen, T. J. (1984). Managing the Flow of Technology. Cambridge, UK: MIT Press.

Argyris, C. (1962). Interpersonal competencies and organizational effectiveness. Homewood II: Irwin, New York.

\begin{tabular}{lll|l}
\hline JISR-MSSE & Volume 11 & Number 1 & Jaunary - June 2013
\end{tabular}


Amundsen, S., \& Corey, E. (2000), Decisions behind career choice for nurse practitioners: independent versus collaborative practice and motivational needs behavior, Clinical Excellence of Nursing Practice, 5(4), 309-315.

Applebaum, S. H., Hebert, D., \& Leroux, S. (1999). Empowerment: power, culture an leadership- a strategy or fad for the millennium. Journal of Workplace Learning: Employee Counseling Today, 2 (7), 233-254.

Australian Manufacturing Council 1994, Leading the way- a study of best manufacturing practices in Australia and New Zealand, AMC: Melbourne, Australia

Baldwin, T.T., Danielson, C., \& Wiggenhorn, W. 1997, The evolution of learning strategies in organizations from employee development to business redefinition, Academy of Management Executive, 11(4), 47-57.

Beaumont, N., Schroder, R., \& Sohal, A. (2002). Do foreign owned firms manage advances and manufacturing technology better? International Journal of Operations \& Production Management, 22(7), 759-771.

Bowen, D. E., Lawler, E. E., (1992). The empowerment of service workers: what, why, how and when? Sloan Management Review, 33(3), 31-40.

Blyth, A. (2004). Ethical Corporation in Asia. New York: Prospect Media.

Cameron, K. (1978), Measuring organizational effectiveness in institute of higher education, Administrative Science Quarterly, 23(4), 604-634.

Campbell, J. P. (1977). On the nature of organizational effectiveness. In P. S. Goodman \& J.M. Penings (Eds.), New Perspective on organizational effectiveness (pp. 13-55). San Francisco, CA: JosseyBass.

Chong, H. (2008). Measuring performance of small and medium sized enterprises, the grounded theory approach, Journal of Business and Public Affairs, 2(1), 1-10

Denton, D. (1998). Better management through budgeting, instilling a quality culture, Management Review, pp.16-18.

Easterby-Smith, M . (1997). Discipline of organizational learning: contributions and critiques, Human Relations, 50(9), 1085-106.

Edelman, L.F., Brush, C.G., \& Manolova, T. S. (2002). The impact of human and organizational resources on small firm strategy, Journal of Small Business and Enterprise Development, 9(3), 236-244.

Etzioni, A. (1973). The third sector in Domestic Mission, Public Administration Review, 33(4), 311-323. 
Grahan, H. (2001). Making the grape wine bear fruit-developing communication competence, Journal of Communication Management, MCB UP Limited, 1, 95-101.

Hayton \& James. (2003). Strategic Human Capital Management in SMEs; an empirical; study of entrepreneurial performance, Human Resource Management (winter). 42(4), 375.

Hoegl, M., WeinKauf, K., \& Gemuenden, H. G. (2004). Interterm coordination, project commitment, and teamwork in multi team $\mathrm{R} \& \mathrm{D}$ projects: a longitudinal study, Organization Science, 15(1), 38-55.

Stephen, F., David, S., \& Yiannis, G. (2005). Organizing and Organization (3 ${ }^{\text {rd }}$ ed). London.

Wendell, F., \& Veena, V. (2009). Organizational Development (6 $6^{\text {th }}$ ed ). USA: Prentice Hall. 